Revista Destaques Acadêmicos, Lajeado, v. 8, n. 3, 2016. ISSN 2176-3070

DOI: http://dx.doi.org/10.22410/issn.2176-3070.v8i3a2016.1128

www.univates.br/revistas

\title{
ASSISTÊNCIA À GESTANTE DE ALTO RISCO EM AMBULATÓRIO ESPECIALIZADO
}

\author{
Luísa Pereira Becker Delwing ${ }^{1}$, Giselda Veronice Hahn²
}

\begin{abstract}
Resumo: O estudo teve como objetivo conhecer a visão das gestantes de alto risco sobre o atendimento recebido em um Ambulatório de Gestação de Alto Risco (AGAR). Tratase de uma pesquisa qualiquantitativa, descritiva, do tipo estudo de caso, realizada com em acompanhamento pré-natal no referido ambulatório. Foram entrevistadas 10 gestantes que apresentaram intercorrências clínicas e que estavam em atendimento no serviço especializado. Os dados foram analisados por meio de estatística descritiva e análise de conteúdo. As gestantes apresentaram diferentes fatores de risco, tendo maior incidência a Diabetes mellitus. Todas as gestantes são oriundas de serviços de Atenção Primária à Saúde. O número de consultas realizadas com a equipe multiprofissional variou de acordo com o fator de risco apresentado. Observou-se o reconhecimento por parte das gestantes de alto risco do trabalho realizado pelo AGAR na prevenção e controle dos fatores de risco para garantir a sua saúde e de seus bebês.
\end{abstract}

Palavras-chave: Gestante. Gravidez de Alto Risco. Ambulatório Especializado.

\section{INTRODUÇÃO}

A gestação é um fenômeno biológico que gera mudanças na vida da mulher, sejam elas físicas, sociais e emocionais. A partir da constatação da gestação, independente se planejada ou não, existe uma série de cuidados a serem realizados. A gestação é vista com naturalidade, por ser uma questão cultural, mas exige cuidados (BRASIL, 2010).

Garantir o pré-natal adequando e humanizar o atendimento às gestantes são metas básicas a serem alcançadas por profissionais e serviços de saúde. Além disso, é preciso dedicar atenção especial a uma parcela de mulheres grávidas que são portadoras de doenças que podem se agravar durante a gestação ou que apresentarão problemas desencadeados nesse período e

1 Enfermeira. Egressa do curso de Enfermagem do Centro Universitário Univates.

2 Doutora em Enfermagem pela Universidade Federal do Rio Grande do Sul, Brasil (2015). Professora da Univates. 
que podem vir a sofrer algum agravo, desenvolver problemas ou apresentar maiores probabilidades de evolução desfavorável, tanto para o feto como para a mãe, como o óbito (BRASIL, 2010).

As estatísticas sobre mortalidade materna têm sido apontadas como melhor indicador da saúde da população feminina e, consequentemente, a melhor ferramenta de gestão de políticas públicas voltadas para a diminuição dos índices ora apresentados. Durante todo século XX foram implementadas ações de prevenção para a redução dos níveis de óbito materno. Apesar de todos os esforços realizados, ainda no século XXI há mulheres que morrem durante o ciclo gravídico-puerperal, sendo $90 \%$ destes óbitos por causas evitáveis e $99 \%$ ocorrendo em países em desenvolvimento (VIANA; NOVAES; CALDERON, 2011).

A mortalidade materna é uma das mais graves violações dos direitos humanos das mulheres. No Brasil dois fatores dificultam o monitoramento da mortalidade materna, a subnotificação das causas dos óbitos e o subregistro dos mesmos na declaração de óbito. O preenchimento incorreto da declaração de óbito ocorre quando é omitido que a morte teve causa relacionada à gestação, parto ou puerpério (BRASIL, 2009).

A redução da mortalidade materna no Brasil ainda é um desafio para os serviços de saúde e sociedade de um modo geral. As altas taxas encontradas se tratam de um grave problema de saúde pública, especialmente por que a maior incidência ocorre em mulheres das classes sociais com menor acesso aos bens sociais (BRASIL, 2009). O Brasil, em conjunto com outros 191 países, comprometeu-se com a redução da mortalidade materna ao assinar o compromisso para diminuição da desigualdade e melhoria no desenvolvimento humano, por meio de oito iniciativas que foram denominadas de Objetivos de Desenvolvimento do Milênio (ODM), entre as quais destaca-se a redução de mortalidade materna.

A Política de Assistência Integral a Saúde da Mulher (PAISM) ampara as mulheres no direito ao pré-natal, que inclui exames, consultas e orientações sobre o local de atendimento e vinculação a este para o seu pré-natal e o parto (BRASIL, 2004). Há evidências científicas de que a mortalidade materna e perinatal é influenciada pelas condições de vida e pela qualidade da assistência obstétrica. Nesse contexto, essa associação entre a qualidade da assistência pré-natal e os indicadores de saúde da mulher é mais evidente quando se constata que 529.000 mulheres morrem a cada ano por causas relacionadas com a maternidade em países em desenvolvimento, sendo que $80 \%$ dos casos se devem a causas obstétricas diretas, e que, para cada mulher que morre, muitas sofrem enfermidades que as incapacitam, de alguma forma, em sua vida produtiva e responsabilidades. Além do mais, podemos observar que quase quatro milhões de recém-nascidos morrem antes de completarem um mês de vida devido a complicações como prematuridade, baixo peso ao nascer e malformações congênitas (MADEIRA, 2011). 
Por isso, a Organização Mundial da Saúde (OMS) recomenda que os serviços de Atenção Básica e Hospitalar desenvolvam ações de forma integrada e continuada em todos os ciclos da vida, de forma que a gestante e o neonato, especialmente aqueles em situação de risco, sejam monitorados pela equipe de saúde (OLIVEIRA; MADEIRA; PENNA, 2011).

Embora as mulheres que apresentam problemas possam necessitar de procedimentos mais complexos, que só podem ser solucionados nos níveis secundários, terciários, com equipe de saúde e tecnologia sofisticadas, alguns casos também podem ser resolvidos no nível primário. A definição do nível de assistência necessário para a solução dos problemas dependerá do problema apresentado e qual intervenção será realizada. As normas de assistência devem permitir identificação precoce e adequada dos problemas que a gestante apresente, assim como os procedimentos diagnósticos e terapêuticos necessários, e em que nível de assistência aos mesmos serão realizados. Os fatores de risco gestacional podem ser prontamente identificados no decorrer da assistência pré-natal, desde que os profissionais de saúde estejam atentos a todas as etapas da anamnese, exame físico geral e exame ginecológico-obstétrico e podem ainda ser identificados por ocasião da visita domiciliar, razão pela qual é importante a coesão da equipe (BRASIL, 2010).

A Portaria $n^{0} 1.459$ de 24/06/2011 (BRASIL, 2011) tem dentre seus objetivos avaliar e classificar a necessidade de aperfeiçoamento no que diz respeito ao atendimento e qualidade do pré-natal, como melhorar a atenção à saúde da criança de 0 a 24 meses, organizar a Rede de Atenção à Saúde Materna e Infantil e reduzir a mortalidade materna e infantil com foco no neonato. $\mathrm{O}$ atendimento pré-natal está organizado atualmente no Brasil por meio da Rede Cegonha, que é estruturada a partir de quatro componentes: prénatal, parto e nascimento, puerpério e atenção à saúde da criança. Dentro dessa regulamentação o MS oferece exames de pré-natal, de teste rápido de gravidez e de detecção da sífilis e HIV, para o aumento e qualificação de leitos em UTI adulto e neonatal e leitos de gestação de alto risco.

A Resolução 203/12, da Comissão Intergestores Bipartite, do Estado do Rio Grande do Sul (RS), cria o Ambulatório de Gestação de Alto Risco (AGAR) que deve atuar integrado ao Sistema Estadual de Referência Ambulatorial no atendimento à gestante e visa à redução de morbimortalidade materna e neonatal. Em seu artigo $3^{\circ}$, dispõe que o AGAR deverá oferecer atendimento multidisciplinar e em regime ambulatorial às gestantes de alto risco ou que necessitem de acompanhamento periódico devido às doenças prévias ou próprias da gestação. O AGAR deve instituir a classificação de risco da gestação de acordo com as diretrizes do Manual de Gestação de Alto Risco do MS de outubro de 2010, ou de atualizações do mesmo. O acesso ao AGAR se dará por meio da Central de Marcação de Consulta Ambulatorial Estadual ou Municipal, preferencialmente no ambulatório de referência da sua regional (RS, 2012). A referida Resolução define a classificação do AGAR da seguinte forma: 
Ambulatório de Gestação de Alto Risco tipo I (AGAR - I): Deve dispor de equipe multidisciplinar de atenção à gestante de alto risco, de equipe fundamental, constituída pelos seguintes profissionais: dois Obstetras com experiência no atendimento à gestante de alto risco por turno de serviço; um Clínico Geral; um Enfermeiro; um Assistente Social; um Psicólogo. O serviço deverá prestar atendimento a toda a gestante classificada como de alto risco, devendo, portanto, manter referência com AGAR - II visando eventuais encaminhamentos (RS, 2012).

Ambulatório de Gestação de Alto Risco tipo II (AGAR - II): Deve dispor de equipe fundamental e de outros cinco profissionais especializados, podendo ser: médico especialista em medicina fetal, endocrinologista, cardiologista, neurologista, geneticista, fisiatra, fisioterapeuta, educador físico, nutricionista ou outros que o serviço entenda ser necessário. O serviço deverá prestar atendimento a toda a gestante classificada como de alto risco e manter apoio matricial também ao AGAR - I (RS, 2012).

O presente trabalho tem como objetivo conhecer a visão das gestantes de alto risco sobre o atendimento recebido em um AGAR.

\section{METODOLOGIA}

Trata-se de uma pesquisa qualitativa, descritiva, do tipo estudo de caso, com gestantes de alto risco em acompanhamento pré-natal em um AGAR-1 localizado num hospital de médio porte no Vale do Taquari/RS. O referido AGAR atende os 37 municípios que compõem a região de abrangência da $16^{\text {a }}$ Coordenadoria Regional de Saúde. Suas atividades foram iniciadas em dezembro de 2013. Com isso os atendimentos que eram encaminhados a outras cidades, principalmente a Porto Alegre e região metropolitana, salvo casos específicos, são realizados na própria região de moradia da gestante, evitando transtornos de transporte, estadia, entre outros.

A amostra foi constituída por 10 gestantes que apresentaram intercorrências clínicas e realizaram o acompanhamento durante o mês de setembro de 2015. A coleta de dados foi feita mediante entrevista semiestruturada, utilizando-se um roteiro norteador. As entrevistas foram realizadas individualmente, em uma sala privativa, localizada no mesmo setor do atendimento, foram gravadas e transcritas posteriormente. Cada entrevista durou em torno de trinta minutos.

Os dados qualitativos foram analisados por meio da análise de conteúdo segundo Bardin (2011), quando se buscou a subjetividade presente nas respostas abertas, por meio de quatro etapas: pré-análise das informações, classificação, categorização e interpretação. Os dados quantitiativos serão apresentados por meio de tabelas e percentuais para uma melhor compreensão dos mesmos e aqueles qualitativos estão organzaidos em categorias analíticas. 
O projeto de pesquisa foi aprovado pelo Comitê de Ética em Pesquisa (COEP), do Centro Universitário Univates, sob o CAEE n ${ }^{\circ}$ 48007715.4.0000.5310. Após os trâmites legais, a pesquisadora fez contato com as gestantes do serviço especializado e as convidou a participar do estudo, explicando o mesmo. Tendo a aceitação dos participantes, foi agendada a entrevista e, antes de iniciá-la, foi lido e explicado o Termo de Consentimento Livre e Esclarecido (TCLE) e solicitada a assinatura do mesmo em duas vias, ficando uma via com o entrevistado e outra com o entrevistador. Essa pesquisa buscou, como benefício, uma ampliação da visão por parte do público sobre o atendimento prestado pelos profissionais às gestantes de risco.

\section{RESULTADOS}

O serviço oferece um ambiente tranquilo e é equipado conforme a Portaria $n^{\circ} 1.459$ de 24/06/2011 (BRASIL, 2011) exige. Ele funciona em horário comercial, de segunda à sexta-feira, com agendamento prévio das consultas. A gestante, ao ser recebida no AGAR, é submetida a uma consulta de enfermagem para levantamento do histórico de enfermagem, verificação dos sinais vitais e realzação da Monitorização da Pressão Arterial (MAPA). A seguir, ela é encaminhada à consulta médica e nutricional. Essa rotina se repete a cada atendimento, cuja periodicidade é definida de acordo com o fator de risco apresentado pela gestante.

Na tabela 1 são apresentados os dados gerais sobre as participantes do estudo. A idade das gestantes teve considerável variação (de 18 a 43 anos). Somente uma (10\%), apresentou idade inferior a 20 anos, quatro $(40 \%)$ tiveram idade entre 20 a 30 anos, três (30\%) de 31 a 40 e duas (20\%) acima de 41 anos. O número de gestações variou de uma a quatro por gestante, a idade gestacional variou de 20 a 36 semanas e duas gestantes apresentaram aborto anterior.

Tabela 1 - Idade, número de gestações, idade gestacional e número de abortos prévios das gestantes acompanahdas no AGAR

\begin{tabular}{c|c|c|c|c}
\hline Gestante & Idade & $\mathbf{N}^{\mathbf{o}}$ gestações & Idade gestacional $^{*}$ & $\mathbf{N}^{\mathbf{0}}$ abortos \\
\hline 01 & 28 & 2 & 20 & 0 \\
02 & 31 & 2 & 21 & 0 \\
03 & 18 & 1 & 31 & 0 \\
04 & 21 & 1 & 34 & 0 \\
05 & 34 & 3 & 23 & 1 \\
06 & 25 & 1 & 36 & 0 \\
07 & 41 & 3 & 22 & 2 \\
08 & 43 & 4 & 34 & 0
\end{tabular}




\begin{tabular}{c|c|c|c|c}
\hline Gestante & Idade & $\mathbf{N}^{\mathbf{0}}$ gestações & Idade gestacional $^{*}$ & $\mathbf{N}^{\mathbf{0}}$ abortos \\
\hline 09 & 32 & 3 & 33 & 0 \\
10 & 23 & 3 & 26 & 1 \\
\hline
\end{tabular}

* em semanas.

Fonte: dados da pesquisa, 2015.

As gestantes apresentaram diferentes fatores de risco. É possível observar a variedade de condições apresentadas pelas mesmas. A Diabetes mellitus gestacional foi o fator de risco preponderante ( $30 \%$ dos casos), seguido pela trombose linfática e idade materna acima de 35 anos ( $20 \%$ dos casos). Cabe observar que a hipertensão arterial sistêmica (HAS) foi encontrada em apenas uma gestante (10\% dos casos). A Tabela 2 apresenta os fatores de risco referidos pelas gestantes:

Tabela 2 - Fatores de risco referidos pelas gestantes que demandaram o atendimento no AGAR

\begin{tabular}{c|l}
\hline Gestante & \multicolumn{1}{c}{ Fator de risco } \\
\hline 01 & Diabetes mellitus gestacional \\
\hline 02 & Trombose linfática 1 \\
\hline 03 & Trombose linfática 2 \\
\hline 04 & Infecção urinária de repetição e 18 anos de idade \\
\hline 05 & Histórico de prematuridade do feto \\
\hline 06 & Eritroblastose fetal* \\
\hline 07 & Hipertensão Arterial Sistêmica e obesidade \\
\hline 08 & Idade acima de 35 anos, dor e sangramento significativo \\
\hline 09 & $\begin{array}{l}\text { Idade acima de 35 anos, diabetes mellitus gestacional e má formação } \\
\text { fetal anterior }\end{array}$ \\
\hline 10 & Diabete mellitus gestacional e epilepsia \\
\hline
\end{tabular}

* Seu fator Rh é negativo, como teve o aborto deveria ter sido administrada a vacina Partogama SDF - imunoglobulina anti-Rho (D). Devido a não administração da vacina realiza o acompanhamento no ambulatório devido ao risco de Eritroblastose fetal.

Fonte: dados da pesquisa, 2015.

As gestantes que participaram do estudo são provenientes de encaminhamentos feitos por profissionais que atuam em Unidades Básicas de Saúde. O número de consultas realizadas com a equipe multiprofissional do AGAR variou entre as gestantes de acordo com o fator de risco apresentado. Todas as gestantes são oriundas de serviços de Atenção Primária à Saúde. As incorrências - Diabetes mellitus gestacional associado à epilepsia, infecção 
urinária de repetição e 18 anos, Diabetes mellitus gestacional e má formação fetal anterior e trombose linfática - foram os fatores de risco que demandaram maior acompanhamento entre as gestantes. A tabela 3 apresenta esses dados.

Tabela 3 - Origem do encaminhamento número de consultas realizadas no AGAR e idade gestacional na chegada ao serviço

\begin{tabular}{c|c|c|c}
\hline Gestante & Origem & Consultas realizadas & Idade gestacional $^{*}$ \\
\hline 01 & UBS** & 02 & 20 \\
02 & UBS & 12 & 21 \\
03 & UBS & 02 & 34 \\
04 & UBS & 19 & 31 \\
05 & UBS & 22 & 26 \\
06 & UBS & 02 & 23 \\
07 & UBS & 06 & 36 \\
08 & UBS & 02 & 22 \\
09 & UBS & 09 & 34 \\
10 & UBS & 04 & 26 \\
\hline
\end{tabular}

* em semanas.

** Unidade Básica de Saúde.

Fonte: dados da pesquisa, 2015.

A relação entre a idade gestacional e o respectivo período de acompanhamento das gestantes é apresentada na Figura 1. Por meio da linha de tendência traçada no gráfico é possível observar que quatro gestantes (01, 04, 05 e 07) possuem um período de acompanhamento reduzido em relação as outras seis $(10,03,09,02,08$ e 06) de acordo com a história prévia ou com o período em que surgiu o fator de risco. 
Figura 1 - Relação Idade Gestacional x Período de Acompanhamento

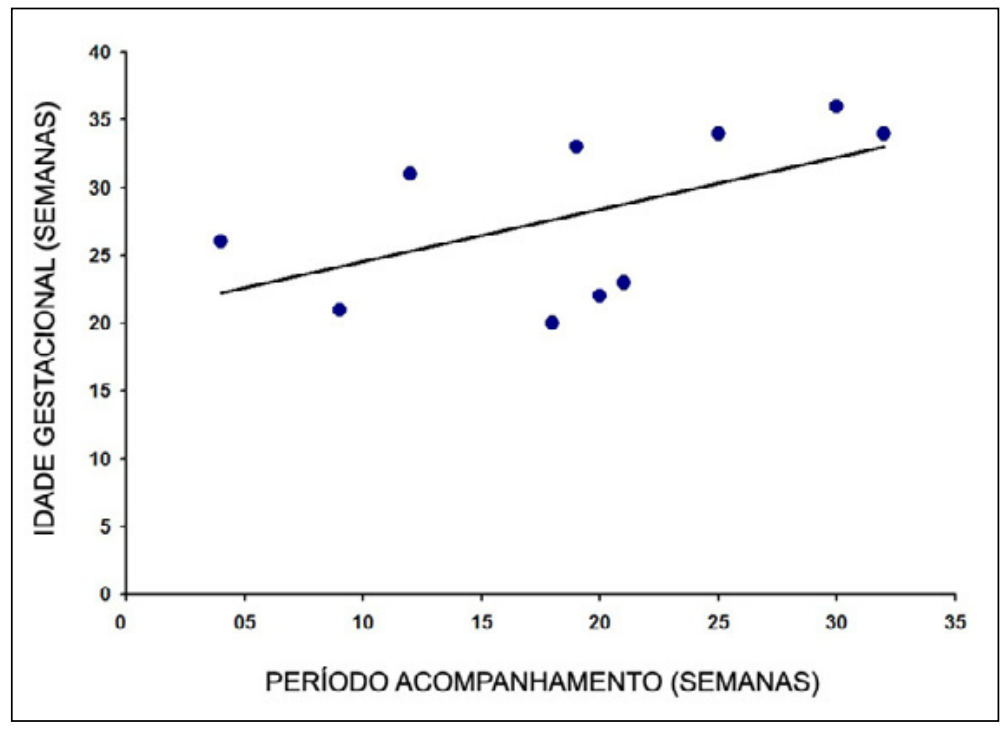

Fonte: dados da pesquisa, 2015.

\subsection{Categorias qualitativas}

Os dados qualitativos foram organizados de acordo com os núcleos de sentido presente nos mesmos (BARDIN, 2011). Das respostas foram retirados trechos relevantes que estão dispostos nos quadros apresentados a seguir. O Quadro 1 apresenta o entendimento por parte de cada gestante sobre o diagnóstico, os riscos envolvidos na gestação e os cuidados necessários. A descrição dos núcleos de sentido está organizada segundo a ordem das gestantes (de 01 a 10) e os fatores de risco estão descritos na Tabela 2 - Fatores de risco referidos pelas gestantes apresentada anteriormente. 


\section{Quadro 1 - Entendimento sobre o diagnóstico apresentado}

\begin{tabular}{|c|c|}
\hline Eixo de análise & Núcleos de sentido \\
\hline $\begin{array}{l}\text { Entendimento das } \\
\text { gestantes sobre } \\
\text { o diagnóstico, os } \\
\text { riscos envolvidos } \\
\text { e os cuidados } \\
\text { necessários. }\end{array}$ & $\begin{array}{l}\text { G1: Diabetes gestacional: o bebê pode nascer com peso muito alto. Faz o } \\
\text { teste de faz Haemoglucoteste (HGT) - controle de glicemia capilar; mais } \\
\text { chance de a gestante ter pré eclampsia, que é a pressão alta. } \\
\text { G2: Trombose linfática 1: uso de Enoxaparina. Esse medicamento é um } \\
\text { anticoagulante (evita que o sangue se coagule dentro do vaso; precisa } \\
\text { cuidar com a alimentação, caso contrário há risco de complicações na hora } \\
\text { do parto como a hemorragia; fazer uso de uma meia compressiva. } \\
\text { G3: Trombose linfática 2: um linfedema durante a gravidez significaria em } \\
\text { um parto de emergência. E dependendo da idade gestacional o bebê não } \\
\text { sobreviveria por ainda não ter formado os pulmões. } \\
\text { G4: Infecção urinária de repetição: risco de um parto prematuro. } \\
\text { G5: Histórico de Prematuridade do feto: se considera bem instruída. Não } \\
\text { pode aumentar o peso corporal, não deve realizar esforços e deve ficar em } \\
\text { repouso. Mas não consegue fazer repouso. } \\
\text { G6: Eritroblastose fetal e causa desconhecida de aborto: aborto com três } \\
\text { semanas na gestação anterior. Deseja o bebê e que nasça bem. } \\
\text { G7: Hipertensão arterial e obesidade: não sabia que haveria tanto risco } \\
\text { para o bebê. Recebeu explicações sobre como agir e cuidados com a } \\
\text { alimentação. } \\
\text { G8: Idade > } 35 \text { anos, dores com sangramento significativo e causa } \\
\text { desconhecida de aborto: não faz uso de medicação, apenas cuidados com } \\
\text { alimentação e com a forma de agir durante a gestação. } \\
\text { G9: Idade > } 35 \text { anos, diabetes gestacional e histórico de má formação } \\
\text { gestacional: entende os riscos e que o bebê pode ser prejudicado e está } \\
\text { ganhando muito peso. Entendeu, logo no início, as orientações dos } \\
\text { médicos e nutricionistas. } \\
\text { G10: Diabetes gestacional e epilepsia: faz HGT - controle de glicemia } \\
\text { capilar, entende e segue as orientações. Faz uso de medicamento para } \\
\text { epilepsia. Não faz uso de insulina. Não tem preocupação, pois não tem } \\
\text { convulsões há anos. }\end{array}$ \\
\hline
\end{tabular}

Fonte: dados da pesquisa, 2015.

No Quadro 2 é apresentada a compreensão das gestantes acerca das orientações sobre saúde feitas pela equipe multiprofissional - se estão sendo seguidas e se são relevantes para a gestante. 
Quadro 2 - Orientações sobre saúde feitas às gestantes pela equipe multiprofissional

\begin{tabular}{|l|l|}
\hline \multicolumn{1}{|c|}{ Eixo de análise } & \multicolumn{1}{c|}{ Núcleos de sentido } \\
\hline & $\begin{array}{l}\text { G1: Sim, é mais na alimentação mesmo, cuidar o que come; } \\
\text { G2: Estou seguindo as orientações, mas não sei que medicamento é esse } \\
\text { que estou fazendo tratamento } \\
\text { G3: Sim, estou usando a meia elástica que me pediram; } \\
\text { G4: Sim, preciso cuidar da alimentação; } \\
\text { G5: Eu tenho medo de perder novamente como foi antes, com três } \\
\text { semanas. Eu fico com medo e por isso eu faço tudo direitinho como eles } \\
\text { pedem. } \\
\text { G6: Estou seguindo tudo. Fiquei muito culpada ao saber que não estava } \\
\begin{array}{l}\text { Orientações } \\
\text { da equipe } \\
\text { multiprofissional } \\
\text { de saúde - se } \\
\text { estão sendo } \\
\text { seguidas e são } \\
\text { relevantes }\end{array} \\
\text { consulta, os médicos explicaram como era, o que é pra comer e não comer. } \\
\text { G7: Agora ta tudo bem. No início eu tinha medo. Mas agora ta tranquilo. } \\
\text { Eles me explicaram tudo. } \\
\text { G8: O atendimento me ajuda, me instrui bastante. Eu já sei como é ter } \\
\text { prematuro. Não posso pegar peso, nem fazer esforço, tenho que ficar me } \\
\text { repouso, mas nem sempre consigo. } \\
\text { G9: Tranquilo, não tive medo. Logo entendi as orientações da } \\
\text { nutricionista. E dos médicos. Eu sei que pode prejudicar o bebê, pois ele ta } \\
\text { ganhando muito peso. } \\
\text { G10: Eu me preocupei se o bebê ia nascer com diabete, por isso faço o } \\
\text { controle do HGT e sigo as orientações. Pra mim foi uma novidade ter que } \\
\text { passar por esse acompanhamento, pois mesmo tendo epilepsia, nas outras } \\
\text { gestações não precisei passar por isso. Mas é bom por que a gente aprende } \\
\text { mais. Eu uso medicamento pra epilepsia e não preciso de insulina. Não } \\
\text { tenho convulsão há anos. }\end{array}$ \\
\hline
\end{tabular}

Fonte: dados da pesquisa, 2015.

No Quadro 3 é apresentada a percepção por parte das gestantes, acerca da importância do atendimento prestados pelo AGAR frente ao medo e insegurança gerados pela situação de risco. 
Quadro 3 - Percepção da importância dos serviços prestados pelo AGAR

\begin{tabular}{|c|c|}
\hline Eixo de análise & Núcleos de sentido \\
\hline $\begin{array}{l}\text { Importância dos } \\
\text { serviços prestados } \\
\text { pelo AGAR frente } \\
\text { ao medo e a } \\
\text { insegurança das } \\
\text { gestantes gerados } \\
\text { pela situação de } \\
\text { risco }\end{array}$ & $\begin{array}{l}\text { G1: O serviço me ajuda muito para controlar a ansiedade, faço o possível } \\
\text { pra tentar controlar. A princípio deu um pouco de medo, mas como não } \\
\text { estou sentindo nada, estou mais tranquila. No momento da realização do } \\
\text { HGT fico tensa para ver o resultado e na verificação da pressão também fico } \\
\text { ansiosa. O serviço é bom porque ajuda quem tem risco. } \\
\text { G2: Aqui é bem legal, me sinto segura. } \\
\text { G3: O serviço é muito bom. Acho que se eu não tivesse vindo para o AGAR } \\
\text { meu filho teria nascido de } 06 \text { meses e talvez não estaria vivo hoje, porque } \\
\text { a minha medica de lá (UBS) queria tirar ele antes. E as médicas daqui } \\
\text { disseram que não, que a gente vai com ele até o final. } \\
\text { G4: Aqui os profissionais têm mais entendimento a respeito do meu } \\
\text { problema. } \\
\text { G5: Eu acho mais seguro vir pra cá, sabe. Aqui a médica é ginecologista. Os } \\
\text { médicos são apropriados pra isso. Tem nutricionista, se precisar. } \\
\text { G6: Eu acho bastante diferente do posto de saúde e pra mim é bem } \\
\text { importante, por que tu sabe que aqui tem profissional que já trabalha com } \\
\text { isso e está acostumado com esses casos, e aí te orienta e te ajuda certo. É } \\
\text { bom o atendimento aqui. } \\
\text { G7: Eu acho que todo mundo deveria ter direito a esse atendimento. } \\
\text { G8: Da outra vez que tive gestação de risco, eu tive que fazer } \\
\text { acompanhamento em POA. Que bom que agora tem o ambulatório aqui. } \\
\text { Eles são especialistas aí a gente se sente mais seguro. } \\
\text { G9: Pra mim foi uma novidade ter que passar por esse acompanhamento. } \\
\text { Acho que todas as gestantes de risco deveriam ter um atendimento assim. } \\
\text { G10: O serviço é bom, me ajuda, me instrui bastante. }\end{array}$ \\
\hline
\end{tabular}

Fonte: dados da pesquisa, 2015.

\section{DISCUSSÃO DOS DADOS}

A idade das 10 gestantes entrevistadas variou entre 21 e 43 anos. Em estudo semelhante realizado com 12 gestantes de risco, Dourado e Pelloso (2007) obtiveram uma variação de idade de 21 a 42 anos. Em relação aos indicadores de gestação de alto risco classificados em biológicos, a idade materna menor que 16 anos ou superior a 35 anos é observada, segundo Freitas e cols. (2011), como fator de risco. Segundo o Ministério da Saúde (BRASIL, 2010) idade materna maior que 35 anos ou menor que 15 anos, ou menarca há menos de 2 anos também representa fator de risco. No presente estudo, nenhuma gestante possuía idade inferior a 18 anos e duas $(20 \%)$ apresentaram idade superior a 35 anos - 41 e 43 anos, respectivamente. Xavier e colaboradores (2013), em estudo descritivo sobre e perfil de risco reprodutivo de 3.440 mulheres matriculadas em um serviço de pré-natal de alto risco, referem que a idade materna acima de 35 anos pode representar uma renda familiar mais elevada, o que agiria com um fator protetor à saúde materna. 
O número de gestações observados foi de três em $40 \%$ das gestantes, uma em $30 \%$, duas em $20 \%$ e quatro em $10 \%$. No estudo de Dourado e Pelloso (2007), a maioria das gestantes, ou seja, 58,3\%, estavam vivenciando a gestação, no mínimo, pela terceira vez. Número semelhante foi relatado no estudo de Xavier e colaboradores (2013), onde 43,9\% referiram duas ou três gestações, $33,5 \%$ referiram uma gestação e $22,6 \%$ referiram quatro u mais gestações.

No estudo de Dourado e Pelloso (2007) os motivos de agendamento no pré-natal de alto risco foram variados, entretanto, houve a predominância da Hipertensão Arterial, estando presente em $66,6 \%$ dos casos. No presente estudo, apenas uma $(10 \%)$ gestante possui a HAS como fator de risco. Esta intercorrência pode sofrer positiva influência da educação em saúde e, portanto, tal fato pode ser explicado pelo atendimento prestado pelo AGAR onde a partir do $1^{\circ}$ encaminhamento é realizada a Monitorização da Pressão Arterial (MAPA) para todas as gestantes, além do encaminhamento para a consulta médica e acompanahmento nutricional.

A hipertensão arterial é a complicação mais frequente na gestação, ocorrendo em 5 a 10\% das futuras mamães, e é responsável pelo maior índice de morbimortalidade materna e perinatal. É a primeira causa de mortalidade materna chega a 35\% dos óbitos é decorrente de eclampsia, hemorragia cerebral, edema agudo dos pulmões, insuficiência renal aguda e coagulopatias. O diagnóstico precoce e tratamento adequado são fundamentais. Para que seja diagnosticada a hipertensão na gravidez, os níveis da pressão arterial (PA) devem ser de: PA sistólica $-140 \mathrm{mmHg}$ e diastólica $-90 \mathrm{mmHg}$, as quais devem ser persistentes para serem consideradas hipertensão. Os objetivos principais são o controle da hipertensão para prevenir hemorragia cerebral, minimizar prematuridade e diminuir efetivamente os riscos para mãe e o bebê (BARROS, 2006).

Além dos níveis de PA deve ser levado em consideração também a idade gestacional (IG), paciente com mais de 20 semanas de gestação e previamente normotensa. Os distúrbios hipertensivos são classificados em Pré-eclâmpsia (PE) leve e grave, e eclampsia. A PE é uma doença hipertensiva específica da gestação que ocorre principalmente na primeira gestação e nos extremos da idade materna. A presença de PE, independente de sua gravidade, determina risco para mãe e risco fetal. É caracterizada por hipertensão, edema e proteinúria. A eclampsia é quando a paciente apresenta, além das manifestações anteriores, convulsões motoras. Em gestantes com PE as convulsões não são causadas pelo sistema neurológico. As convulsões podem acontecer até 48 horas depois do parto. As pacientes que permanecem hipertensas após 12 semanas são classificadas como hipertensas crônicas e caso voltem ao normal são classificadas como transitórias (BARROS, 2006).

As causas da hipertensão gestacional não estão devidamente esclarecidas, mas tais distúrbios podem ser muito nocivos para a gestante e o bebê. Na PE os sinais mais importantes são a PA alterada e nível alto de 
proteinúria, que é a presença de proteína na urina, porém, esses sintomas podem passar despercebidos pela gestante. Caracteriza-se por vasoespasmo, redução de volemia e ativação do sistema de coagulação. $O$ feto pode ser gravemente afetado pela má perfusão. A PE leve pode rapidamente evoluir para uma PE grave e assim ser classificada como eclampsia, causando o descolamento prematuro de placenta (DPP), insuficiência renal e ou hepática, edema pulmonar e hemorragia cerebral. A PE leve pode ser tratada em casa com repouso, e a gestante é orientada a ficar o máximo de tempo em decúbito lateral, melhorando o fluxo sanguíneo uteroplacentário. Se o tratamento domiciliar não for eficaz, a gestante terá que ser hospitalizada até que estabilize seus sintomas. A PE grave que se manifestar subitamente deve ser tratada de maneira agressiva, pois impõe uma ameaça ao feto e a mãe. $\mathrm{O}$ atendimento consiste em estabilizar a PA e prevenir convulsões, pois as mesmas podem ser fatais. Serão usadas medicações conforme os sintomas e a conduta médica será definida de acordo com suas particularidades (BARROS, 2006).

Mulheres que são acometidas por hipertensão arterial sistêmica (HAS) na gestação devem ser submetidas a um acompanhamento logo após o parto e ser devidamente orientada sobre os riscos de uma futura gestação e de um possível desencadeamento de doenças cardiovasculares (BRASIL, 2010).

No presente estudo, o fator de risco preponderante foi o Diabetes mellitus gestacional em três (3) das 10 gestantes (30\% dos casos). Mussacatti, Pereira e Maioli (2012), ao analisarem prontuários de 396 gestantes que realizaram o prénatal em Unidades Básica de Saúde constataram em 23 (5,8\%) o diagnóstico de Diabetes Gestacional com valores superiores a $92 \mathrm{mg} / \mathrm{dL}$ de Glicemia de Jejum. Segundo Maganha el al. (2003), a incidência do Diabetes mellitus é variável, estimada em 3\% a $8 \%$ das gestantes. Mesmo sem resultados diretamente relacionados ao alto risco, devemos nos basear em Paes (1998), que ressalta a importância clínica dos resultados em detrimento dos resultados estatísticos. Segundo a autora, os resultados e o diagnóstico fisiológico do indivíduo não deve ser julgado pela estatística, e sim, pelos profissionais da área em que a pesquisa está sendo feita.

A diabetes gestacional é a intolerância aos carboidratos de qualquer intensidade que indica ou é reconhecida pela primeira vez na gestação, podendo persistir após o parto. O diagnóstico se faz a partir de alguns fatores, sendo eles: idade igual ou superior a 35 anos; sobrepeso e obesidade; antecedente de diabete gestacional; malformação fetal em gestação anterior; síndrome de ovários policísticos; hipertensão; crescimento fetal excessivo ou polihidrâmnio. É rotina no pré-natal as gestantes realizarem teste de glicemia no início da gestação, antes das 20 semanas. O rastreamento é positivo quando o nível de glicose plasmática em jejum for igual ou superior a $85 \mathrm{mg} / . \mathrm{O}$ rastreamento deve ser confirmado através de um novo exame, o Teste Oral de Tolerância à Glicose (TOTG). A gestante será submetida em jejum a ingestão de 75 gramas de glicose diluídos em 250 até $300 \mathrm{~mL}$ de água. Após uma hora da ingestão deverá 
ser realizado nova coleta sanguínea e após a segunda hora a coleta deve ser repetida. Os resultados maiores ou igual a 95, 180 e $155 \mathrm{mg} / \mathrm{dL}$ respectivamente confirmam o diagnóstico de diabetes gestacional (BRASIL, 2010).

O tratamento da diabetes gestacional consiste em promover a evolução normal da gestação. $\mathrm{O}$ atendimento pré-natal deve ser realizado por equipe multidisciplinar preparada para a assistência de complicações materna e fetal. É de vital importância que orientações referentes a nutrição, atividade física e monitorização metabólica sejam dadas às gestantes. As gestantes com diabetes dever seguir uma dieta fracionada, mas que preencham suas necessidades sem causar hipoglicemia, hiperglicemia pós-prandial, ou aumento excessivo de peso. A glicemia deve ser controlada rigorosamente, cinco vezes ao dia, por meio do HGT. Quando o tratamento não for eficaz através do controle da dieta, a gestante passará por avaliação para iniciar o uso de insulinoterapia, cujas dosagens são individualizadas para cada caso, sendo um esquema que atenda as necessidades da paciente em questão. $\mathrm{O}$ uso de antidiabéticos orais não é recomendado para gestantes (OPPERMANN; REICHELT, 2006).

As complicações mais comuns no bebê ocasionadas pela diabetes gestacional são as seguintes: macrossomia fetal, classificada quando o recémnascido (RN) pesa entre $4.000 \mathrm{~g}$ e $4.500 \mathrm{~g}$. Ao nascer estes bebês tem um tamanho desproporcional dos ombros, tronco e tórax, ou seja, aumentados, sendo assim, as chances de cesarianas são maiores devido ao risco de distocia de ombro, podendo causar fratura de clavícula no RN.As gestantes podem apresentar cetoacidose metabólica devido à hiperglicemia (CASHION, 2014).

No pós-parto os níveis de glicemia devem ser controlados durante dias. $\mathrm{Na}$ maioria das vezes as mulheres com diabetes gestacional não fazem mais uso de insulina. É importante passar por uma avaliação após seis semanas do pós-parto, repetindo o (TOTG 75) para o diagnóstico da diabetes após gestação, algumas se tornam diabéticas em até 10 anos após a gestação ou logo após a gestação (BRASIL, 2010).

Na Figura 1, quando relacionamos a idade gestacional com o período de acompanhamento ( $\mathrm{n}^{\mathrm{o}}$ de consultas) baseados nos resultados da Tabela 3. Por meio da linha de tendência traçada no gráfico é possível observar que quatro gestantes $(01,04,05$ e 07$)$ possuem um período de acompanhamento reduzido em relação as outras seis (10,03, 09, 02, 08 e 06). Aqui cabe o esclarecimento de que as gestantes abaixo da linha de tendência não estão em desatenção ou tiveram um atendimento tardio, mas sim que, foram encaminhadas pelas UBS de acordo com a história prévia ou com o período em que surgiu o fator de risco.

Isto se evidencia na explicação do MS (BRASIL, 2010), que a presença de um ou mais fatores de risco, na maioria dos casos, indicam a necessidade de maior atenção da equipe de saúde a essas gestantes, realizando consultas e visitas domiciliares com maior frequência, com intervalo definido de acordo com o fator de risco identificado e a condição da gestante no momento. Além 
disso, esta equipe de saúde deve estar atenta aos fatores de risco e identificar o momento em que a gestante necessitará da assistência especializada ou de interconsultas com outros profissionais (BRASIL, 2010).

Também Freitas (2006), explica que a identificação de gestantes de alto risco faz com que a equipe disponha de instrumentos discriminadores no processo de recomendar, gerar e proporcionar cuidados à saúde possibilitando avaliações no processo de referência e contra-referência. A triagem das gestantes de alto risco é realizada no serviço de origem, ou seja, na UBS onde a mesma iniciou o pré-natal. Deve-se perceber qualquer exposição de risco já na primeira consulta do pré-natal e constatar o quanto podem influenciar negativamente na gestação. A assistência no pré-natal deve ser de qualidade, o profissional deve conhecer e entender a gestante deixando-a falar sobre seus medos e anseios já que é uma fase de muitas mudanças físicas e psicológicas, o profissional deve debater e num discurso de fácil entendimento deve esclarecer as dúvidas e expor os cuidados que essa gestante precisa ter, para que a mesma possa ser tranquilizada diante dessa situação.

Em relação às categorias qualitativas: entendimento sobre o diagnóstico apresentado, percepção da importância dos serviços prestados pelo AGAR e orientações da equipe multiprofissional de saúde ficou evidente a qualidade de serviço que pode ser prestado por um serviço especializado na condução da gravidez de alto risco.

Tal fato se evidencia ainda mais quando comparado a estudos que tiveram como tema caracterizar o atendimento pré-natal na Rede Básica de Saúde. Isso pode ser observado no relato de Costa e colaboradores (2013):

Os resultados evidenciaram inadequações relacionadas ao início tardio do pré-natal, à realização da ultrassonografia e à baixa participação em atividades educativas. $\mathrm{O}$ índice de Kessner modificado por Takeda indicou baixo nível de adequação do prénatal (35\%). Identificou-se a necessidade de promover intervenções em saúde para melhorar o acesso precoce das gestantes ao prénatal e monitorar o cumprimento dos protocolos assistenciais preconizados para garantir uma prática segura de cuidados à saúde durante a gestação, parto e puerpério (COSTA et al., 2013, p. 516).

Outro fator está na localização do serviço ser na própria região de moradia das gestantes, o que facilita o atendimento em muitos aspectos: facilidade do acesso com redução das distâncias percorridas, redução do tempo para o atendimento, e principalmente, o descongestionamento dos atendimentos na capital Porto Alegre. E as próprias gestantes relataram, como visto no Quadro 3, com a segurança e tranquilidade que lhes é transmitida por um serviço especializado localizado próximo a elas. 


\section{CONSIDERAÇÕES FINAIS}

As gestantes demonstraram terem maior ciência dos riscos que correm em função da gestação de alto risco após terem iniciado o acompanhamento no AGAR. A Diabetes mellitus foi o fator de risco mais incidente, associado a outras condições clínicas como epilepsia, infecção urinária de repetição, má formação fetal anterior e trombose linfática. Essas gestantes foram as que demandaram maior acompanhamento por parte dos profissionais do serviço. Todas as gestantes são oriundas de serviços de Atenção Primária à Saúde e todas reconhecem a importância do acompanhamento recebido como forma de garantir a sua saúde de seu futuro filho.

Com esse trabalho reforça-se a necessidade de os profissionais de saúde investirem em atividades de educação para a saúde, de maneira que as mulheres e seus familiares sejam esclarecidos quanto aos fatores de risco e suas complicações, pois hipertensão gestacional, diabetes gestacional e obesidade são fatores evitáveis, de modo contribuir para redução da mortalidade materna e neonatal e das complicações acarretadas por tais fatores.

\section{REFERÊNCIAS}

BARDIN, Laurence. Análise de conteúdo. 1. ed. São Paulo: Edições 70. 2011. 229p.

BRASIL. Ministério da Saúde. Conselho Nacional da Saúde. Portaria n 766, de 21 de dezembro de 2004. Brasília, 2004. Disponível em: <http:/ /bvsms.saude.gov.br/bvs/ saudelegis/sas/2004/prt0766_21_12_2004.html>. Acessado em: 15 mar. 2015.

BRASIL. Ministério da Saúde. Guia de vigilância epidemiológica do óbito materno. 1. ed. Brasília: Editora do Ministério da Saúde, 2009. 84p. Disponível em: <http:/ /bvsms. saude.gov.br/bvs/publicacoes/guia_vigilancia_epidem_obito_materno.pdf $>$. Acesso em: 20 abr. 2015.

BRASIL. Ministério da Saúde. Secretaria de Atenção à Saúde. Departamento de Ações Programáticas Estratégicas. Gestação de alto risco: manual técnico. 5. ed. - Brasília: Editora do Ministério da Saúde, 2010. 302 p. - (Série A. Normas e Manuais Técnicos). Disponível em: <http://bvsms.saude.gov.br/bvs/publicacoes/gestacao_alto_risco. pdf >. Acesso em: 03 abr. 2015.

BRASIL. Ministério Da Saúde. Conselho Nacional da Saúde. Portaria n 1459 de 24 de junho de 2011. Brasília, 2011. Disponível em:<http://bvsms.saude.gov.br/bvs/ saudelegis/gm/2011/prt1459_24_06_2011.html>. Acesso em: 23 mar. 2015.

BRASIL. Ministério Da Saúde. Conselho Nacional da Saúde. Portaria n ${ }^{\circ} 650$ de 5 de outubro de 2011. Brasília, 2011. Disponível em:< http://bvsms.saude.gov.br/bvs/ saudelegis/sas/2011/prt0650_05_10_2011.html>. Acesso em: 23 mar. 2015. 
BRASIL. Ministério Da Saúde. Conselho Nacional de Saúde. Resolução n 203/12 de 14 de maio de 2012. Brasília, 2012. Disponível em: <http:/ / www.saude.rs.gov.br/ upload/1339445690_cibr203_12.pdf>. Acessado em: 18 abr. 2015.

CALDAS, Denise B. e colaboradores. Atendimento psicológico no pré-natal de altorisco: a construção de um serviço. Psicol. hosp. São Paulo, v.11, n.1, pp. 66-87, 2013.

CASHION, Kitty. Distúrbios Endócrinos e Metabólicos na Gravidez. In:

LOWDERMILK, Deitra L.; et al. Saúde da mulher e enfermagem obstétrica. 10. ed. Rio de Janeiro: Elsevier, 2013. 1024p.

CHEMIN, Beatriz F. Manual da Univates para trabalhos acadêmicos: Planejamento, elaboração e apresentação. 2. ed. Lajeado: Univates. 2012. 310 p.

COSTA, Christina S. C. e colaboradores. Características do atendimento pré-natal na Rede Básica de Saúde. Rev. Eletr. Enf. [Internet], v.15, n. 2, pp. 516-522, abr/jun 2013. Disponível em: <https://www.fen.ufg.br/fen_revista/v15/n2/pdf/v15n2a26.pdf>. Acesso em: 20 nov. 2015.

DOURADO, Viviani G; PELLOSO, Sandra M. Gravidez de alto risco: o desejo e a programação de uma gestação. Acta paul. enferm. [Online]. v.20, n.1, pp. 69-74. 2007. Disponível em: <http:/ / www.scielo.br/pdf/ape/v20n1/a12v20n1.pdf>. Acesso em: 03 nov. 2015.

FREIRE, Cláudia M. V.; TEDOLDI, Citânia L. Hipertensão arterial na gestação. Arq. Bras. Cardiol. [Online], vol.93, n.6, pp. 159-165, 2009. Disponível em: <http:/ /www. scielo.br/pdf/abc/v93n6s1/v93n6s1a17.pdf>. Acesso em: 20 nov. 2015.

FREITAS, Fernando e colaboradores. Rotinas em obstetrícia. 6. ed. Porto Alegre: Artmed, 2011. 904p.

FUSTINONI, Suzete M. Síndromes Hipertensivas na Gravidez. In: BARROS, Sonia M. O. Enfermagem no ciclo Grávidico-puerperal. 1. ed. São Paulo: Manole, 2006. 259p.

MAGANHA, Carlos A. e colaboradores. Tratamento do diabetes melito gestacional. Rev. Assoc. Med. Bras. [online]. 2033, vol.49, n.3, pp. 330-334. 2003. Disponível em: <http://www.scielo.br/pdf/ramb/v49n3/a40v49n3.pdf>. Acesso em: 20. nov. 2015.

MASSUCATTI, Lais A; PEREIRA, Roberta A.; MAIOLI, Tatiani U. Prevalência de diabetes gestacional em unidades de saúde básica. REAS, v.1, n.1 , pp. 70-79, 2012. Disponível em: <http:/ / www.uftm.edu.br/revistaeletronica/index.php/enfer/ article/download/329/279>. Acesso em: 11 nov. 2015.

OLIVEIRA, Virgínia J.; MADEIRA, Anézia M. F. Interagindo com a equipe multiprofissional: As interfaces da assistência na gestação de alto risco. Esc. Anna Nery [online], v.15, n.1, pp. 103-109, jan./mar. 2011. Disponível em: <http:/ /www. scielo.br/pdf/ean/v15n1/15.pdf>. Acesso em: 10 mar. 2015. 
OLIVEIRA, Virgínia J.; MADEIRA, Anézia M. F.; PENNA, Cláudia M. de M. Vivenciando a gravidez de alto risco entre a luz e a escuridão. Rev. Rene, Fortaleza, v.12, n.1, pp. 49-56, 2011. Disponível em: <http:/ / www.revistarene.ufc.br/revista/ index.php/revista/article/view/108/36 >. Acesso em: 22 abr. 2015.

OPPERMANN, Maria L. R.; REICHELT, Angela Jacob. Diabete Melito e a Gestação. In: FREITAS, Fernando; et al. Rotinas em obstetrícia. 6. ed. Porto Alegre: Artmed, 2010. 904p.

PAES, Ângela T. Itens essenciais em bioestatística. Arq. Bras. Cardiol. [online]. v.71, n.4, pp. 575-580, 1998. Disponível em: <http:/ /www.scielo.br/pdf/abc/v71n4/ a03v71n4.pdf>. Acesso em: 15 nov. 2015.

ESTADO DO RIO GRANDE DO SUL. SECRETARIA DA SAÚDE. Resolução N² 203/12 - CIB / RS. Cria os Ambulatórios de Gestação de Alto Risco (AGAR) no Estado do Rio Grande do Sul. Disponível em: http:/ / www.saude.rs.gov.br/ upload/1339445690_cibr203_12.pdf. Acesso em: 20 out 2015.

VIANA, Rosane da C.; NOVAES, Maria R. C.; CALDERON, Iracema M. P. Mortalidade materna - uma abordagem atualizada. Com. Ciências Saúde, v.22 n.1, pp. 141-152, 2011. Disponível em: <http://www.escs.edu.br/pesquisa / revista/2011Vol22_16mortabilidade.pdf>. Acesso em: 23 mar. 2015.

XAVIER, Rozania B. e colaboradores. Risco reprodutivo e renda familiar: análise do perfil de gestantes. Ciênc. saúde coletiva [online]. v.18, n.4, pp. 1161-1171. 2013. Disponível em: <http:/ /www.scielo.br/pdf/csc/v18n4/29.pdf>. Acesso em: 03 nov. 2015. 